\title{
Heterarchy of General Intellect
}

\author{
IGOR KRASAVIN \\ Ural Federal University, 51 Lenina Street, Yekaterinburg, Russia \\ Email: krasavin.@gmail.com
}

\begin{abstract}
This paper explores the problem of General Intellect, which is analysed in the post-Operaismo intellectual movement. Reflecting the thinking of A. Negri, M. Lazzarato, P. Virno, M. Pasquinelli and others, General Intellect is given here as a synonym of society's cognitive capacity that could either provide liberation from capitalism or be exploited by it. In this paper General Intellect is represented as a property of a social connection structure, called heterarchy. As a connection structure, heterarchy forms different kinds of singularities - finite objects composed of multiple social ties. These aggregations are made by statistical repetitions of relations and individual agents that make values through their goal setting and other intellectual activity. The main argument of the article is that although General Intellect may denote capacity for society's self-organization, it is difficult to identify it with only one particular institutional organisation or political regime. General Intellect appears in any type of social structuring through self-organising processes.
\end{abstract}

Keywords: general intellect, heterarchy, multitude, society, self-organisation, agent, aggregate

\section{INTRODUCTION}

The initial metaphor of General Intellect was invented by K. Marx in his 'Fragment on Machines'. It represents a comparison of labour's machinic organisation to the knowledge of a human mind materially produced by brain. Later it was popularized by Italian (post)Operaismo representatives. Literary, General Intellect is made of social relations with the intentional knowledge and appears as a connection structure and value. General Intellect's creative productivity should overcome the limitations imposed by capital and grant the society its political and economic freedoms (Lazzarato, Negri 1991; Virno 2004). However, there is another point of view, which assumes that the General Intellect as a social and communicative ability, or a kind of 'social brain', with the help of IT-technologies is appropriated by the new 'society of control'. Contemporary development of media and Internet makes human relations more available for observation and control, which improves their appropriation and exploitation (Pasquinelli 2013: 1-20; Vercellone 2007: 13-36). Continuous scanning of people's communication enables capital to mediate its dissemination and transformation from information into knowledge, with an ability to manipulate the 'economy of attention' for the purposes of 'cognitive capitalism' (Pasquinelli 2009; Terranova 2012).

In this paper, the notion of General Intellect is compared with the 'heterarchy' concept that originated in early theories of artificial neural networks that define the connection 
structure and the value formation principle. The concept of heterarchy, in spite of its heuristic value, is not clearly defined yet. The main commentary was provided by W. S. McCulloch (McCulloch 1945), an author of the first theoretical artificial neural network model, in his research of brain neurones. McCulloch associated the heterarchy of values with the concept of the whole. Different parts of such an entity tie together each single entity and contribute to its changes. That makes the logical law of transitivity - the transfer of features from one object to another without any alterations - no longer applicable.

Concerning our research, heterarchy is a multitude of hierarchies, connected by networks and composing aggregations of actors and relations. This structure is heterogeneous, which means that actors and relations are exterior to each other. My argument is that heterarchy is a structure of General Intellect and as such may clarify its composition, its properties as general for society and its capacity to have intellect. Without this, General Intellect remains no more than a beautiful metaphor. Heterarchy is embedded in theoretical connections between various kinds of approaches to social multiplicity inspired by G. Deleuze. The main target of my investigation is a reasoning by A. Negri and other (post)operaists, whose concepts will be analysed through the lenses of heterarchy.

\section{HETERARCHY AND MULTITUDE: CONNECTION STRUCTURE FOR SOCIAL COMPLEXITY}

Multitude is the main concept in General Intellect theory - the visible part of social cognition representing groups and individuals. The concept was borrowed by A. Negri from A. Matheron and means a decentralized organization of relations that represent the association process forming social groups from the sets of individuals (Matheron 1988: 370-371; Negri 1991: 109, 140). Multitude members become singularities, social objects, structurally located between particular individuals and the general collectivity of society. Though in later Latin multitudo was referred to as a crowd or a mass, Spinoza in his unfinished Political Treaty attributes multitudo to the meaning of society as an association before establishment of a certain political order. A swarm of politically acting and negotiating people form conatus, which is reflected in their striving for the establishment of political order brought automatically by inertia of consent. In contrast to the theory of social contract, an organisational process is guided by individual actors' decisions at a microscale. These decisions automatically establish political order by simple aggregation followed by contractual institutions (Matheron 1997: 207-219; Balibar 2008: 69-71).

Multitude is a revolutionary force, proposed instead of nation or class as a terrain for social cognition and organisation. So, multitude is a form of plural organization, which has capacity for political self-organization (Negri 2002). He attacks the concept of the people, a terrain for sovereignty, and describes multitude as a multiple order and a multiple structure, where parts and whole are ontologically equivalent. This kind of organization has no center, no exact border (an ontological 'apartheid' between more and less real entities) or aim. Negri advocates Deleuzian understanding of multiplicity. Ontologically, as pointed out by Deleuze and Guattari, parts and whole are the same, since parts may form many different wholes for the same relations (Deleuze, Guattari 2003: 2-12).

Negri asserts that multitude is a network of actors, ties, values and other parts. In his opinion, multitude is a rhizome (Negri 2002). Interpreting society as multitude means that there are many different social forms united only by their relation to an object. Anyone can be a part of multitude and contribute to 'the primary fount of the valorisation of the world' by any intellectual activity. Multitude continually strives between activities of singularities - individuals, 
groups and communities with metastable identifications. The flow of becoming singularities makes multitude the irreversible continuum of relations. Irreversibility of multiple relations overcomes any institutional restriction. It equally establishes and destroys any social ties. This dynamic social structure is driven by the 'teleology of common', where the common is a name for intersubjective cooperation. The common does not only unite. It is also the basis for General Intellect that comes from living labour in the form of information and knowledge. By sharing information, knowledge and activities, multitude may establish a true communistic order via ontological features of the social structure.

For Negri, multitude is a hope for emancipation, but there are two problems arising from these speculations. First, how do you turn ontological presence into a political order? In other words, irreversibility and plurality of multitude do not aim toward a particular regime. If multitude is the multitude, it has to establish all kinds of relations and types of actors that simultaneously compete and collaborate with each other (Thacker 2004). Multitude does not serve anyone, it does not have an order. Liberation from one order means obedience to another one: that is an ontological plurality of society. Therefore, as E. Thacker points out, multitude is a network that presupposes diverse topologies of relations that cannot be grouped into one hierarchical structure as they are different. It defines itself depending on its topologies (kinds of relations, orders, types of actors, etc.) (Thacker 2004).

The second problem focuses on the commonality of the 'common'. Negri writes that the common is singular, differently affecting each member of multitude (Negri 2003: 182). Ironically, this means that the common does not belong to multitude, so the common simply is not common, but exterior, i.e. not only shared but also divided. Commonality of the common is formal and provides different actors with different fruits of labour. So, it is difficult for the common to unify plurality by imposing a teleology of common cooperation. If we wish to have a dynamic, singular structure of relations that exists inside a self-organization without a command center, then we need to suggest that an order is recursive and comes from the exterior. This literally means that the order comes from other people as individuals and groups (singularities) that are plural and cannot be totally subjugated to any kind of a general goal of a common cooperation.

Heterarchy, established by the forbiddance of transitivity, may appear as a suitable concept for a structure as a multiple order that avoids a vicious circle of the 'common' cooperative teleology. Heterarchy holds the whole and its parts as immanent multiple entities that have different meanings depending on the environment. It recursively combines different wholes that co-exist together. Heterarchy is exterior and temporarily irreversible, since the meaning of relationships changes with any deviation from one state to another (Von Goldammer et al. 2003). Otherness, or exteriority, is extremely important here, as it is not enough to say that heterarchy is just a multiple structure. In this case, it could be a polyarchy or a network and would not be a subject to a new concept. Heterarchy reflects the fact that relations and their meanings are not only multiple but also singular, i.e. finite with series of embodiments. This means that the same relation may contain many different meanings for a particular group or an individual. Statistical multitudes emerge on relational activity of individuals organizing the process of automatic causation. As they emerge, they are not guided by any kind of teleology (Kerimov 2019: 18-21). The structural process goes from the outside for any part and whole. Relations with various meanings or agencies are tied together without 'common' intention.

When individuals and groups become singularities, i.e. relational objects, they cannot be any longer identified with a particular attribute, rationality, profession or ethnicity as they 
begin to carry multiple identifications. Reproducing new attributes brings recursiveness to a network of singularities. Overlapping network relations produces recursive hierarchies that emerge on multiple associations between singularities. Hierarchy, as well as network, originates from the inner multiplicity. Multiple networks accompany hierarchies and recursive hierarchies accompany networks. Relations remain multiple by means of networks, but localized by matching hierarchies. As a result, elements in two different hierarchies can interact only within the boundaries of the third, partially common or differentiated hierarchy. A network from one hierarchy cannot be moved into the space of another hierarchy or establish an equal relationship with it. In a manner of speaking, hierarchies multiply in the process of network differentiation. That is why social relations tend to be conservative, whilst elements of one hierarchy are passive in their relations with elements found in other hierarchies.

Nevertheless, everyone participates in creation of social praxis as a production of subjectivities and relations, i.e. each singularity participates in the society as a whole, and not just inside certain hierarchies (Negri 2002). Networks of singularities, but not hierarchies of identities, are a proven tool for the ordered systems multiplication. By a singular nature of the social form, activity spreads through mobile networks making subjugation of heterarchy (as a social connection structure) to the particular institutional order impossible. Since social relations are network-forming hierarchies, heterarchical organization automatically emerges depending on singularities activity. Its relational assemblage is metastable, so positions of singularities in a connected structure and their activity are mutually dependent. Their connections line up through topological distribution and temporal irreversibility of ties. Time is irreversible, but relations can be reversed. Types of relations are finite, but the variety of situations is infinite.

\section{SOURCES OF GENERAL INTELLECT}

Multitude of hierarchies is united by General Intellect, which is defined as a form of social communication that produces subjectivities and knowledge. Then the question is: who produces General Intellect? As explained earlier, multitude consists of singularities: individuals and groups with multiple identifications. They share information, striving for action and then collectively revolutionize through statistical aggregation. In addition, General Intellect (and that is the origin of its revolutionary force) produces and shares knowledge exploited by capitalism. Knowledge requires another mode of organization and another type of an actor rather than singularity and aggregate. An agent is another type of an actor that seeks goals and produces knowledge, and hierarchy is another mode of organisation. Hierarchy emerges through recursiveness of relations in overlapping networks of singularities. Besides this, hierarchy appears as a mode for the interior reproduction of singularities. Recursion of relations provides opportunity for their temporal and finite manipulation. Hierarchy reduces multiplicity to the simulation of unity through coincidence of reasons and goals of relations and the point of coincidence is hierarchy itself. Therefore, via delay and operation of time, it interiorises the relations and properties of singularities. With the help of hierarchy, singularities mediate processes, assemble ties and synthesise values (senses), i.e. appear as goal seeking agents, which depend on aggregations.

Though individual singularities automatically establish the multitude as an aggregate with the properties of a whole, it is rather difficult to impute universal values or volition, or any other characteristics of an agent. So, an exteriorly hierarchic aggregate is based on statistical repetition and automatic action, and an interiorly hierarchic agent on knowledge 
and values (meanings, identifications). Different kinds of individual singularities demonstrate different levels of agency. Individuals are the main mediums and finite 'corporeal' aggregates that manifest themselves as agents. The next type is an organisation consisting of persons' aggregation united by hierarchy of reproducing relations (institutions). Multitude (community) is the most general aggregation that possesses properties of agency randomly, since its borders are vague and hierarchy is external.

We may see that aggregation and agency supplement each other and the latter represents development of the former, though remaining exterior. This power of the agent is more successful as it is supported by fluctuations of aggregates. The agent and any hierarchical institutions are limited by their finite goals and capacity for volition, which at a macro scale make them similar to aggregates, actuated by repetition of relations. That is why irreversible motion of aggregates is able to overcome the power of the agent. The process, in which the agent and aggregate correspond to each other, is a 'living labour', or 'the common' that is multiple and in any particular case overcomes exploitation by a particular mode of relations (Negri 2003: 225-235).

'Living labour' means variable labour, with an absence of strict means for its evaluation. If information and knowledge cannot be totally located, they also cannot be manipulated by attribution to certain properties. They are displaced, remaining at the same place; one who gives it does not lose it. These properties of information and knowledge are long known, but our task is to understand relations that produce and organize information and knowledge, as the common, into General Intellect as a whole.

Although the common cannot be reified, it is nevertheless structured in some way. Information and knowledge have differences as they form different objects. Information as a collection of data is an aggregation, or an aggregative state of knowledge. As such, information has no qualitative properties, but only quantitative. Information turns to knowledge when it is attributed to the agent, i.e. to the actor with certain goals and actions. Therefore it depends on the actor, will the data be recognized as information or as knowledge. It is no exaggeration to say that knowledge defines an actor's capacity to have a spectrum of goals, consequences of actions that make its subjectivation. An actor, the aggregate of properties and qualities, turns to an agent with its own set of goals. Of course, we may continue that each agent is a part of general aggregations and some of them (as groups, organisations) also possess some properties of an agent.

Depending on the environment and configuration of ties, individual singularity differently transforms information to knowledge and differently uses it. Information naturally circulates inside of a particular community. Through organisational hierarchy, community acquires better cognitive capacities realized in goal setting activities. This contributes to a concealment of information and increase of knowledge. Institutionally reproducing community, acting like a kind of agent, as a mediator may exploit 'structural holes' (Burt 2004: 349-352) in the social whole to extract benefits and power. In its turn, power, especially power of the capital, excels by governing social ties as aggregates. Here, we have two sides to the operation of aggregates. On the one hand, opportunity for their exploitation by the agent means that total overcoming of inequality will never come. On the other hand, the lack of total control by the agent means the inevitable overcoming of any totalitarianism, which always remains temporary and partial. This means that 'making multitude' as well as its exploitation is an endless process, which never ends. General Intellect provides opportunities for both sides of the issue and may be used equally for liberation as well as hegemony. 


\section{HETERARCHY AND GENERAL INTELLECT}

Let us examine opportunities and limits of General Intellect exploitation using the example of the 'living labour' management in IT companies and the possible threats to society. Corporate sociology (after the followers of A. Gramsci) has already become aware of cognitive organization and provided some reasoning on the subject. In his research, D. Stark writes about a new kind of managerial organisation in terms that are almost indistinguishable from the concept of General Intellect given by P. Virno (Virno, 2001). This new organization represents a form of 'distributed intelligence in which units are laterally accountable according to diverse principles of evaluation' (Stark 2011: 19). According to Stark, this happens in the process of brokerage and entrepreneurship among companies when specific individual and hierarchized organizations mediate the work of other actors or include them in their system of relations. In other words, one hierarchical organization, which has access to another, can contribute to the establishment of a certain joint structure of relations. For Stark, this structure represents 'organization of dissonance' making social complexity work for the different accounts of worth. For Virno (and Negri definitely would agree with this) 'distributed intelligence' is that very General Intellect, associated with emergent variative social structure. Surprisingly, the theory of corporate management, inspired by the example of Silicon (V)Alley with its programmers' informal communication style, came to the same conclusions as the Italian Operaismo thinkers. What is more surprising, the name for the new kind of structure given by Stark was heterarchy.

Put into practice, this method of organization could solve the main problem of social theory. More specifically, there is a difference between structure and action, between action and cognition. Stark proposes to merge aggregative social complexity and goal setting activity of an agent in the organizational structure. However, this technique is really just an exception to the rules. In social practice, heterarchy (and its promising economic prospects in the form of distributed intelligence) is actually hardly susceptible to formalization. The irreversibility of time and topological distribution of processes, leading to complexity of relations, is the main impediment. Every hierarchic organization is a kind of agent, limited by its own goals. Linear merger usually leads to interruption of their work. Of course, they can establish a mediator, but that organization, which is also an agent, will be limited by its own finite goals. If it will absorb the previous two organisations and redistribute their tasks and results, we will have a hierarchy but not heterarchy. Presence of goals and values points at the limited nature of an organisation, which is subordinated to the hierarchical order, whereas heterarchy, being multiple, overcomes a particular order as many different orders as aggregations of singularities. Different hierarchies belong to different situations (localities in heterarchical space of relations), while their connections establish the third situation, which is not associated with the targets of the first two and so on. This way of change is endless and heterogeneous. Total subordination of social ties is impossible and that makes total subordination of General Intellect also impossible. This changes the course of singularities' relations and their choice-making. Like heterarchy, General Intellect is experienced as virtual, but is it possible that a virtual entity could be exploited by the powers of domination, as well as by those of liberation, concerning some particular issues?

Like heterarchy, General Intellect excels any hierarchical order with imposed goals, be it liberation or exploitation. As a connection structure, heterarchy reveals properties that make limited opportunities to exploit General Intellect as well as use it to overcome capitalism (or any other social order). Due to irreversibility of time and topological configuration of ties, any 
particular singularity, an aggregate or an agent with its political or economic goals, will always depend on its location in the connection structure. All that heterarchy and General Intellect can do is to provide opportunities for aggregation of agents. These entities do not serve for a particular social order because they produce all the orders simultaneously.

As the brain does not suspect the existence of personality, General Intellect, made by social heterarchy, is also not aware of 'cognitive capitalism'. Owing to the difference of aggregates and agents, General Intellect has no agency, therefore it cannot be subjugated, though it is partially possible to operate the capacity of its self-organisation. Even if General Intellect is assimilated to assemblage of information machines, as Pasquinelli puts it (Pasquinelli 2009), such an exegesis will be insufficient. Information machines are organized around certain functions and have no agency, i.e. do not appear as a species that make a decision (transform information to knowledge) on their own in the process of the irreversible time. If there is no common agency - there is no General Intellect that seeks a particular goal, only self-organisation of singularities' aggregation.

\section{CONCLUSIONS}

The model of heterarchy provides opportunities and imposes limitations on social relations and therefore casts light on the extent to which General Intellect can be embodied in the virtual structure of social connections and their specific institutional organizations. If General Intellect is something more than a metaphor, then the restriction of transitivity and uncontrollable complexity should become its inherent properties.

Society with a heterarchical structure is always the General Intellect since it self-organizes inside the irreversible time through its association of heterogeneous relations. It frames the experience and the automaticity of action but denies its reflection as a source of organization. Some opportunities provided by the General Intellect can be used, but it cannot be forced to conform to a specific institutional order. Control and variation have the same source - hierarchies of relations proliferate in a heterarchy while networks remain the tool of proliferation. Along with control and application methods, the General Intellect produces methods of liberation which come laden with new limitations. By destroying industrial institutions, network organization has brought new control hierarchies. This process is irreversible and is only partially controllable: the processes and composition of topological distribution can vary while self-organization of multitude always remains exterior to any social order.

\section{References}

1. Balibar, E. 2008. Spinoza and Politics. London, New York: Verso.

2. Burt, R. 2004. 'Structural Holes and Good Ideas', American Journal of Sociology 110(2): 349-399.

3. Deleuze, G.; Guattari, F. 2003. A Thousand Plateaus: Capitalism and Schizophrenia. London, New York: Continuum.

4. Kerimov, K; Kerimov, T. 2019. 'Nancy, Descartes and Continuous Creation', Kronoscope 19(1): 18-21.

5. Lazzarato, M.; Negri, A. 1991. 'Travail immateriel and subjectivite', Futur Ante'rieur 6.

6. Matheron, A. 1988. Individu et Communaute chez Spinoza. Paris: Minuit.

7. Matheron, A. 1997. The Theoretical Function of Democracy in Spinoza and Hobbes. Minneapolis: University of Minnesota Press.

8. McCulloch, W. 1945. 'A Heterarchy of Values Determined by the Topology of Nervous Sets', Bulletin of Mathematical Biophysics 7: 89-93.

9. Negri, A. 1991. The Savage Anomaly: The Power of Spinoza's Metaphysics and Politics. Minneapolis: University of Minnesota Press. 
10. Negri, A. 2002. Approximations Towards an Ontological Definition of the Multitude. Available at: https:// www.generation-online.org/t/approximations.htm

11. Negri, A. 2003. Time for Revolution. New York: Continuum.

12. Pasquinelli, M. 2009. 'Google's PageRank Algorithm: A Diagram of the Cognitive Capitalism and the Rentier of the Common Intellect', in Deep Search: The Politics of Search Beyond Google, eds. K. Becker and F. Stalder. London: Transaction Publishers.

13. Pasquinelli, M. 2013. 'Italian Operaismo and the Information Machine', Theory, Culture \& Society 32(3): 49-68.

14. Stark, D. 2011. The Sense of Dissonance: Accounts of Worth in Economic Life. Princeton: Princeton University Press.

15. Terranova, T. 2012. 'Attention, Economy and the Brain', Culture Machine 13: 1-19.

16. Thacker, E. 2004. 'Networks, Swarms, Multitudes', CTheory 18/05/2004. Available at: https://ctheory.net/ articles.aspx?id $=422$

17. Vercellone, C. 2007. 'From Formal Subsumption to General Intellect: Elements for a Marxist Reading of the Thesis of Cognitive Capitalism', Historical Materialism 15(1): 13-36.

18. Virno, P. 2001. 'Entry', in Lessico Postfordista, eds. A. Zanini and U. Fadini. Milan: Feltrinelli.

19. Virno, P. 2004. A Grammar of the Multitude: For an Analysis of Contemporary Forms of Life. Los Angeles, New York: Semiotext(e).

20. Von Goldammer, E.; Paul, J.; Newbury, J. 2003. 'Heterarchy - Hierarchy: Two Complementary Categories of Description', in Vordenker. Webforum for Innovative Approaches in Sciences, Economy and Culture. Available at: https://www.vordenker.de/heterarchy/a_heterarchy-e.pdf

IGOR KRASAVIN

\section{Bendrinio intelekto heterarchija}

\section{Santrauka}

Straipsnis skirtas bendrinio intelekto problemai, kuri analizuojama postoperaizmo intelektualiniame judejjime. Apmąstant A. Negri, M. Lazzarato, P. Virno, M. Pasquinelli ir kitų mintị, bendrinis intelektas čia pateikiamas kaip sinonimas visuomenès pažintinès gebos, kuri gali arba išlaisvinti nuo kapitalizmo, arba būti jo išnaudota. Straipsnyje bendrinis intelektas pristatomas kaip socialinio ryšio struktūra, vadinamoji heterarchija. Kaip ryšio struktūra, heterarchija suformuoja skirtingų rūšių singuliarumus - baigtinius objektus, sudarytus daugybiškų socialinių saitų. Šiuos agregatus sukuria santykių ir individualių veikejjų, kuriančių vertes nustatant tikslus ir kitą intelektinę veiklą, statistiniai pasikartojimai. Pagrindinis šio straipsnio argumentas tas, kad, nors bendrinis intelektas gali reikšti visuomenès saviorganizacijos gebą, sunku ji identifikuoti su tik viena kuria nors institucine organizacija ar politiniu režimu. Bendrinis intelektas pasirodo bet kurio tipo socialiniame struktūravime saviorganizacijos procesais.

Raktažodžiai: bendrinis intelektas, heterarchija, daugybiškumas, visuomenė, saviorganizacija, veikejjas, agregatas 